\title{
Understanding the Requirements of Applied Evidence-Based Decision Making in Social Protection Policies in Egypt
}

\section{Saudi Mohamed Hassan (PhD)}

Associate Professor - Department of Social Planning

Faculty of Social Work,-Assiut University

Dr. Ahmed Thabet Helal Ibrahim

Associate Professor - Department of Casework

Faculty of Social Work,-Assiut University 
The Egyptian Journal of Social Work (EJSW) https://ejsw.journals.ekb.eg/e ISSN: 2356-9204 Vol 11, Issue.1, January2021 
The Egyptian Journal of Social Work (EJSW) https://ejsw.journals.ekb.eg/e ISSN: 2356-9204

Vol 11, Issue.1, January2021

\section{ABSTRACT}

Evidence-based decision-making is of great importance in professional interventions, in social work, within many areas of professional practice. One of the important areas of social work, in the Egyptian environment, is the field of economic Aids. In this field, social workers provide all economic aids to applicants as a kind of social protection provided to them by countries including the services of the social welfare policies in Egypt.

The current study explores the requirements of applied evidence-based decision making, in social protection policies, in Egypt. The purpose of this study is to determine the requirements (knowledge, skill, and value) that are necessary for evidence-based decision-making in social protection policies. The sample of this study consists of 71 social workers from Assiut City, Egypt, 39 males, and 32 females, ages 28 through 60 years. Finally, strategies for helping social workers ton incorporating evidence-based decision making in social protection policies in Egypt are suggested.

Keywords: Evidence-based decision making, Social protection, Social Policy.

\section{INTRODUCTION}

The social work profession with its various branches, like all other human professions, went through many stages of development and upgrading which coped with the successive changes in the human society resulting from the technological progress and the communication revolution that made the world a small village. It was normal for these developments to have severe effects on the reconsideration of many concepts of social work. Hence, it was inevitable that the profession of social work should be developed and should activate its view of the nature of customer problems and the methods of dealing with them by making a link with many scientific theories and applied models that formed, in the end, the professional practice of social work (Abdel-Majeed et al., 2008, p3)

In this context, programs of professional intervention for social work have witnessed a quick development during the past two decades. This development features have appeared in the transformation from focusing on psychological subconscious factors far from measurement and observation to procedural factors and causes which are subjected to the features of clinical measurement and accurate scientific observation. In the light of this transformation, the social worker's task is no longer a kind of luxury or time consumption. It is also no longer an act based on improvisation and guesswork. 
Rather, it has become a planned scientific and systematic work governed by goals and is expected to offer concrete and desirable results which contribute to reducing people sufferings and helping them to discover their energies and invest them optimally. (Mansour, 2010, P.5)

With the development of professional practices in social work, appeared what became known as Evidence-Based Practice which is one of the concepts that emphasize the importance of training practitioners who are able to make appropriate decisions based on realistic observations depending on the results of experimental research. This reduces bias and leads to a practice of high efficiency and effectiveness. (Zidan et al., 2016, P. 105)

In recent years, there has been a growing interest, by governments around the world, for paying attention to evidence-based policies and practices when making decisions related to the provision of services to citizens, with the aim of providing high-quality services to these citizens. (Maynard, 2006)

The follower of the beginning and emergence of the term decision-making finds that this concept has been studied and analyzed by researchers from various academic and scientific fields such as economics, statistics, medicine, psychology, nursing, accounting, finance, marketing, and management since hundreds of years ago. These sciences made many contributions that clarified and developed this concept. Therefore, the emergence of the concept of decisionmaking, in social work literature, is relatively recent. The real emergence of this term is attributed to the 1960s with the emergence of a Problem-Solving Model of Hellen Parlman. This concept reappeared strongly with the profession focus and reliance on evidence-based practice in 1990. (Howell, 2009)

In the context of attention to the process of client participation in therapeutic decision-making, emerged, in 1999, the book of Terence O'Sullivan entitled "Decision-Making in Social Work". This book was dedicated entirely to the decision-making process in social work. The author of this book indicated that the decision-making process is the basic activity, in the social work, which needs to be given special importance by practitioners and researchers. The book also focused on the fact that the decision-making represents the heart of social work as a professional basic activity. It goes into various tasks and stages of professional intervention in the social work starting from association, assessment, planning, implementation of the plan, evaluation, review, termination, and ending intervention. The social 
workers, then, need to be educated and constantly trained on the issue of including the participation of the client in decision-making because decisions taken in social work are in real need of great care. Decisionmaking is a basic skill that should be properly trained on and prepared when conducting professional interventions with clients. (O'Sullivan, 1999)

Payne has pointed out that decision-making is one of the core values of the ethical charter of social work, which is the client's direct involvement in decision-making, particularly those decisions that directly affect the client. (Payne, 1989)

Thyer indicated that decision-making in social work is the process that involves the steps of professional intervention starting from the association with the client, assessing the problem, planning for the professional intervention then, implementing the intervention and furthermore, finishing and follow-up. The result of this process comes from reaching a final decision regarding the client's problem through the use of different skills afforded by the professional intervention. (Thyer, 2013)

The decision-making process has also been defined as an intellectual and objective work that seeks to choose the most suitable alternative among multiple alternatives available to the decisionmaker, as mentioned above, through comparing between them with criteria that serve this purpose taking into account the internal and the external circumstances facing the decision makers. (Ibrahim, 2017)

Howell (2009) displayed that decision-making is the key skill in working with the individuals and the families, as all social service activities depend on customer decision-making. (Howell, 2009, p. 59)

\section{LITERATURE REVIEW}

There are a lot of researches in literature which have dealt with evidence-based practice in social work, as well as the process of decision-making in education and in the practice of social work separately regarding studies that dealt with evidence-based decisionmaking. There are few studies which were conducted with the aim of addressing the evidence-based decision-making process in social work and nearby specialties, especially in both health and education fields. The study of Stamatakis et al, 2017 tried to design a tool to measure and evaluate the effectiveness of evidence-based decision-making in public health institutions. (Stamatakis et al., 2017) The study aimed at designing a tool to evaluate knowledge in evidence-based decisionmaking in the health care providers' practice aiming at providing the 
The Egyptian Journal of Social Work (EJSW) https://ejsw.journals.ekb.eg/e

ISSN: 2356-9204

Vol 11, Issue.1, January2021

best care for patients. This tool can be used to support the development of continuing education programs to enhance efficiency.

Majdzadeh's study explained the difficulties that prevent the application of evidence-based decision-making for Iran health policy makers. It indicated that these difficulties included the characteristics of decision makers, the decision-making environment, the selection criteria of decision makers, the attitudes of practitioners towards adopting the decision-making process in working with the targets, the weakness of cooperation between sectors, and the unspecified priorities.

The Baba \& Hakem study explained the need for managers to have reliable evidence so that they can make strong and effective decisions related to the services provided to customers. The study suggested a mixed multi-leveled model of evidence-based decisionmaking, an. It referred to the need for evidence-based decision-making to be at the heart of management education as well as in training programs to enhance evidence-based decision-making in organizations.

The study of Wentworth et al. showed how research practice partnerships can be used as a strategy to promote evidence-based decision-making among teachers in schools. It discussed what the impact of these partnerships is in improving the quality of educational services.

Stonebraker\& Howard's study, (2018), designed an introductory course that incorporated evidence-based decisionmaking. It explained the importance of teaching students the decisionmaking process as well as methods of collecting and managing information. It also taught students to be aware of decisions, to create the decision-making process and to practice decision-making.

Through the results of the previous studies, researchers found that there is a research gap in research conducted on evidence-based decision-making in the Egyptian environment, especially in the field of economic assistance. This study is considered to be the first study to address the issue of evidence-based decision-making in the field of social protection policies in Egypt. 
The Egyptian Journal of Social Work (EJSW) https://ejsw.journals.ekb.eg/e

ISSN: 2356-9204

Vol 11, Issue.1, January2021

\section{THEORETICAL FRAMEWORK \\ SOCIAL PROTECTION POLICIES IN EGYPT}

The main objective of social protection policies is to enhance access to services and resources to support families and poor groups in mitigating risks and vulnerability. The social protection policies also targeted ensuring the minimum extent of welfare by ensuring that essential goods and services which provide emergency living protection are provided to all people. In addition, they reduce poverty among members of society by promoting opportunities for sustainable development. (Abu Al-Maati, 2002)

The mechanisms of social protection policies, in Egypt, are reflected through the role of the country in providing social protection policy to the groups that are entitled to it because of its political, economic, financial, and legal potentials. Among the most important policies of Egypt to provide social protection to citizens are the followings:

\section{(1) Social Security System:}

Social security is a human right which governments are committed towards their citizens by providing an appropriate level of health care to individuals and by ensuring a decent life for individuals who do not have an adequate standard of living due to income shortfalls or individuals living in poverty (Al-Amry, 2000). Social Security aims at ensuring that the individual receives an income that replaces his wage when he or she is interrupted by a breakdown, an illness, or an injury. It includes old-age pension which also includes a benefit in the case of death of the breadwinner. Its purpose is also to meet exceptional expenses such as in cases of childbirth, death, and marriage (Al-Azi, 2011).

There are two types of social security assistance (Al-Bayoumi, 1997):

1. Assistance for ongoing pensions for widows with children, orphans, the elderly, and the totally disabled.

2. Assistance that is disbursed in one go or in payments for the subsidy cases estimated by the Minister of Social Affairs.

\section{(2) Solidarity and Dignity Program}

The Solidarity and Dignity Program is the conditional cash transfer program launched by the Ministry of Social Solidarity in Egypt in 2015. It comes under the umbrella of developing social safety nets which is one of the mechanisms of the Ministry of Social Solidarity to develop social protection systems and link them to development indicators for promoting access to basic rights for poor families such as health, education, proper nutrition, access to 
employment opportunities and citizens' protection. It also contributes to social security by alleviating poverty and developing human capital by benefiting from educational and health services and awareness workshops to obtain a new generation with the ingredients for integrated and sustainable development. Hence, the Program of Solidarity and Dignity was introduced under the slogan "Egypt without Need" through the provision of monthly income to poor families, yet it is subjected to the extent to which families are committed to shared responsibilities (Ministry of Solidarity, 2017). This program includes:

A. Solidarity: includes groups that are extremely poor and need cash and service support, so that they can produce and invest in their children from day one to 18 years (e.g. for families living in poor rural and urban areas).

B. Dignity: includes groups that are severely poor or aren't able to work or produce and therefore, they need social protection, such as the elderly, 65 years old and above, without a fixed pension and those with a full or partial disability. (Solidarity, 2018)

\section{(3) Social Insurance}

Social insurance is "a system which ensures that the insured or his family are compensated for the loss of earnings in the event of a risk that leads to his inability to work, and thus get paid, as well as the provision of treatment and rehabilitation services. This system is based mainly on collecting subscriptions in advance to result in benefits, in emergencies, to which the insured is exposed. (Al-Hoot, 1990)

\section{(4) Social Assistance}

Social assistance includes all services and cash given to those in need at the expense of the country budget free of charge including the elderly, the sick, children, orphans and the disabled. It is provided on the basis of economic and social needs, or on the basis of average needs. The size of such assistance is determined by the circumstances of the needy and the resources of the country. (Abu Al-Maati, 2002)

In order to activate social protection policies, an integrated anti-poverty strategy must be developed aiming at raising the economic and the social level of the most deserving groups (Hamza, 2015) including: 
The Egyptian Journal of Social Work (EJSW) https://ejsw.journals.ekb.eg/e

ISSN: 2356-9204

Vol 11, Issue.1, January2021

1. Developing appropriate mechanisms to improve the living conditions of the poor and open the economic and investment opportunities available to them through training and employment programs, and financing for small enterprises.

2. Developing a plan to strengthen social protection networks for people whose standard of living is deteriorating to a low level. This can be achieved through the development of a provision, in the public budget, where sufficient funds are allocated to support the poor and the needy.

3. Creating an effective system for financing social protection network funds as the deduction of certain percentages of salaries, wages, profits, and revenues and placing them in a private investment fund owned by employees and workers who have been fired from their jobs to provide them with continuous income.

4. Establishing professional training and rehabilitation programs for surplus workers to allow them to enter a new career that guarantees them at least the same income prior to the privatization process.

5. Upgrading social services, such as basic health and education services regarding the need to provide them free of charge and considering their utilization as an absolute right of citizenship.

6. Expanding social security networks, doubling the number of beneficiary families, and using the guide of human development indicators in identifying target groups and geographical distribution.

\section{Purpose of the Study}

This cross-sectional study seeks to understand the requirements of applied evidence-based decision-making, in social protection policies, in Egypt. Considering the following points:

1. Determining the requirements (knowledge, skill, and value) that are necessary for evidence-based decision-making in social protection policies.

2. Determining the reality and the level of the application of evidence-based decision-making in social protection policies.

3. Identifying the relationship between the availability of requirements (knowledge, skill, and value) and evidence-based decision-making in social protection policies.

4. Identifying the relationship between the personal and professional variables of social workers working in social protection policies and their tendency towards the application of evidence-based decision-making. 
The Egyptian Journal of Social Work (EJSW) https://ejsw.journals.ekb.eg/e

ISSN: 2356-9204

Vol 11, Issue.1, January2021

\section{Research Hypotheses}

\section{Method}

\section{Study Design:}

The current study is a part of a cross-sectional study designed to assess the requirements of applied evidence-based decision making in social protection policies in Egypt.

\section{Population and Sample:}

The study population included 71 selected social workers. The workers at Eastern Asyut, Western Asyut , Abnoub, and Al-Fath Social Administration in Asyut Governorate are responsible for the Solidarity and Dignity Program implemented by the Egyptian government represented in the Ministry of Social Solidarity. Participants are given questionnaires to fill out. The selection of participants was based on a purposive sampling technique. Data was collected in 2020.

\section{Data Collection Procedure and Ethical Considerations}

For this study, we created and administered a survey with a cover letter explaining the purpose of the study, the potential confidentiality issues, and an informed consent to the respondents. The consent was obtained from each of the social workers. Letters were sent from the Faculty of Social Work at Asyut University to the Social Solidarity Directorate in Asyut Governorate in Egypt, before distributing surveys to social workers in Family Dispute Settlement Offices. The data collection process lasted for 25 days.

\section{Measurement Instrument}

This survey included 74 items and lasted from 10 to 15 minutes to be fulfilled. For investigating the requirements of the application of decision-making based on evidence (knowledge, skill, and value) at the social units in Asyut governorate, Egypt, 27 items have been examined. 7 other items were used to investigate demographic variables such as gender, age, education level, social status, employment level, experience years, and, if any, the completed training courses. 40 items assess the reality of applying social workers to decision-making steps based on evidence in working with clients benefiting from the Solidarity and Dignity Program in social units in Asyut Governorate.

Response options were presented on a five-point Likert-scale assessing agreement with the stem: $1=$ strongly disagree, $2=$ disagree, $3=$ neither agree nor disagree, $4=$ agree, and $5=$ strongly agree. The final instrument was reviewed for content validity by six 


\begin{tabular}{||cr|}
\hline The Egyptian Journal of Social Work (EJSW) https://ejsw.journals.ekb.eg/e \\
ISSN: $2356-9204$ & Vol 11, Issue.1, January2021 \\
\hline
\end{tabular}

social work professors with expertise in this area in order to assure that the survey content was appropriate. They are consulted to express opinion about the validity of the study tool in terms of the linguistic integrity of the phrases and their association with the variables to be measured. The approval was based on an agreement percentage of (83.33). Additionally, internal consistency of the instrument was determined through calculating the correlation between each dimension of the instrument and the total score of the instrument using Pearson for a sample of 10 social workers outside the research sample. This is shown in the table (1).

Table (1): the correlation coefficient between the scores of each questionnaire item and the total number of questionnaire scores $n=10$

\begin{tabular}{|r|l|c|}
\hline No & \multicolumn{1}{|c|}{ Dimensions } & $\begin{array}{c}\text { Pearson Correlation } \\
\text { Significant }\end{array}$ \\
\hline 1 & The first-dimension requirements & $.494^{*}$ \\
2 & $\begin{array}{l}\text { The second-dimension evidence-based decision } \\
\text { making }\end{array}$ & $.950^{* *}$ \\
\hline
\end{tabular}

*. at the 0.05 level **. at the 0.01 level

Reliability: Cronbach's alpha was used to calculate the reliability of the measurement scale. From the statistical analysis, it can be concluded that the instrument was reliable as a score of 0.779 and was obtained for the items. See (Table 2). The table below shows that most of the coefficients of the variables have a high degree of reliability. Their results are reliable, and the tool is finalized.

Table (2) Shows reliability $\mathrm{n}=10$

\begin{tabular}{|r|l|l|c|}
\hline No & \multicolumn{1}{|c|}{ Dimensions } & N of Items & Cronbach's Alpha \\
\hline 1 & $\begin{array}{l}\text { Total requirements and evidence-based } \\
\text { decision making }\end{array}$ & 3 & 0.779 \\
\hline
\end{tabular}

\section{Ethical Considerations}

Prior to data collection, ethical clearance was obtained from the Directorate of Social Solidarity in Asyut Province. In addition, verbal consent from the respondents was obtained from social workers working in the Solidarity and Dignity Program at the social units of Asyut city prior to the commencement of the study.

\section{Data Analysis}

Data analyses were performed using SPSS for Windows 20.0 (Armonk, NY: IBM Corp.). Descriptive statistical techniques were applied to clarify demographic characteristics of the study sample. Such techniques included the frequencies and percentages were calculated and (mean, median and standard deviation) were determined for each Likert-scale item. Lastly, Pearson Correlation 


\begin{tabular}{||cr|}
\hline The Egyptian Journal of Social Work (EJSW) https://ejsw.journals.ekb.eg/e \\
ISSN: $2356-9204$ & Vol 11, Issue.1, January2021 \\
\hline
\end{tabular}

Significant and Cronbach's alpha to assess the reliability of the study tools and measure the strength of the tools' consistency.

\section{RESULTS}

\section{Demographic Information}

The demographic variables information of the participants is represented in Table (3). For gender, it is 39 (54.9\%) for males and 32 $(45.1 \%)$ for females in favor of male participants. For age, the majority of participants, $32(45.1 \%)$, are 30: 39 years old; while 16 respondents $(22.5 \%)$, are less than30 and 40-49 years old and 7 (9.9 \%) 50-59 years old (M 36.19).

For the social status, 47 (66.2\%) of participants are married 17, $(23.9 \%)$ are single, and $7(9.9 \%)$ are divorced. For the level of education, the majority of participants $31(43.7 \%)$ are a Bachelor's of Social Work (BSW) holders, 23 participants $(32.4 \%)$ are a BSW of Arts, Department of Sociology, holders, 7 (9.9\%) one or more Diploma holders, and 10 (14.1\%) Master's in Social Work (MSW) holders.

For the employment status, $46(64.8 \%)$ of participants are working as social workers, $16(22.5 \%)$ as field researchers, $6(8.5 \%)$ as head of a social unit, and only $3(4.2 \%)$ as department managers.

For years of experience, 37 participants $(52.1 \%)$ have from 10 to 20 years of professional experience, $26(36.6 \%)$ less than 10 years, $7(9.9 \%)$ have from 20 to 30 years of professional experience, and only 1 participant $(1.4 \%)$ has more than 30 years. (M 13.66).

For the completed training courses, 17 participants (47.2\%) completed 4-7 training courses, $13(36.1 \%)$ completed more than 7 training courses and $6(16.7 \%)$ completed 6 training courses (M 3.41).

Table (3) demographic variables $n=71$

\begin{tabular}{|c|c|c|}
\hline Variables & Frequency & $\%$ \\
\hline \multicolumn{3}{|l|}{ 1- Gender } \\
\hline Male & 39 & 54.9 \\
\hline Female & 32 & 45.1 \\
\hline Total & 71 & 100 \\
\hline \multicolumn{3}{|l|}{ 2- Age } \\
\hline Less than 30 & 16 & 22.5 \\
\hline $30-40$ & 32 & 45.1 \\
\hline $40-50$ & 16 & 22.5 \\
\hline $50-60$ & 7 & 9.9 \\
\hline Total & 71 & 100 \\
\hline Mean & 36.19 & \\
\hline \multicolumn{3}{|c|}{ 3- Social Status } \\
\hline Single & 17 & 23.9 \\
\hline Married & 47 & 66.2 \\
\hline
\end{tabular}




\begin{tabular}{||cr||}
\hline The Egyptian Journal of Social Work (EJSW) https://ejsw.journals.ekb.eg/e \\
ISSN: $2356-9204$ & Vol 11, Issue.1, January2021 \\
\hline \hline
\end{tabular}

\begin{tabular}{|l|l|l|}
\hline Divorced & 7 & 9.9 \\
\hline Total & 71 & 100 \\
\hline 4- Educational level & \multicolumn{2}{|l|}{} \\
\hline diploma in social work & 7 & 9.9 \\
\hline Bachelor of Social Work (BSW) & 31 & 43.7 \\
\hline Bachelor of sociology & 23 & 32.4 \\
\hline Master's in social work & 10 & 14.1 \\
\hline Total & 71 & 100 \\
\hline 5- Employment Status & \multicolumn{2}{|l|}{} \\
\hline Department manger & 3 & 4.2 \\
\hline Social worker & 46 & 64.8 \\
\hline Head of a social unit & 6 & 8.5 \\
\hline Field Researcher & 16 & 22.5 \\
\hline Total & 71 & 100 \\
\hline 6- Years of Experience & \multicolumn{2}{|l|}{} \\
\hline Less than 10 years & 26 & 36.6 \\
\hline 10-20 & 37 & 52.1 \\
\hline 20-30 & 7 & 9.9 \\
\hline More than 30 years & 1 & 1.4 \\
\hline Total & 71 & 100 \\
\hline Mean & 13.66 & \\
\hline 7- Number of Training courses & \multicolumn{2}{|l|}{} \\
\hline Less than 4 & 6 & 16.7 \\
\hline 4-7 & 17 & 47.2 \\
\hline More than 7 & 13 & 36.1 \\
\hline Total & 71 & 100 \\
\hline Mean & 3.41 & \\
\hline & \multicolumn{2}{|l|}{} \\
\hline
\end{tabular}

The table No. 4 refers to the most important requirements for the application of decision-making based on evidence in social protection policies at social units in Asyut Governorate. These requirements are arranged as follows:

The First Dimension: values requirements with an average of (1.78) and a standard deviation of (.098) Such as values of fairness and equality when providing services respecting individual beneficiaries' differences, appreciating their feelings, preserving the confidentiality of information, respecting the privacy of clients to gain their trust and the importance of forming a professional relationship with clients benefiting from units, placing customer interests and problems as a priority for professional work, accepting, and respecting all beneficiaries who are dealt with.

The Second Dimension: knowledge requirements with an average of (1.77) and a standard deviation of (.137). We consider the basic knowledge about social protection policies and the living situation of families benefiting from the Solidarity Program. We also consider the basic conditions for eligibility to the Program and the exclusion 


\begin{tabular}{||cr|}
\hline \multicolumn{2}{|c|}{ The Egyptian Journal of Social Work (EJSW) https://ejsw.journals.ekb.eg/e } \\
ISSN: $2356-9204$ & Vol 11, Issue.1, January2021 \\
\hline
\end{tabular}

criteria from obtaining the Solidarity Program support. knowledge about the use of the computer (tablet) in registering cases and the availability of information and databases about the groups benefiting from units. In addition to preparation of follow-up reports about the families benefiting from the Solidarity and Dignity Program.

The Third Dimension: skill requirements with an average of (1.74) and a standard deviation of (.21)

There exist communication skills choosing the most appropriate alternative to explode the needs of clients, social research skills, differentiation between alternatives, determining family priorities, using technology and computers to register families, research skills in databases, and follow-up skill to serve clients of the Solidarity and Dignity Program for the benefiters of social security units in Assiut Governorate.

Looking at the table, the results indicate that the general average of the order of requirements for the application of decision-making based on evidence in social protection policies in social units in Asyut Governorate reached (1.76) which is an average rate. This makes us accept the first assumption of the study which means that the (knowledge of value skills) are expected to be available for decisionmaking based on evidence among social workers working in the Solidarity and Dignity Program at an average level.

Table (4) Shows the level requirements $n=71$

\begin{tabular}{|l|l|c|l|l|c|}
\hline No & Dimensions & mean & SD & Level & Rank \\
\hline 1 & knowledge requirements & 1.77 & .137 & Moderate & 2 \\
\hline 2 & Skill requirements & 1.74 & .21 & Moderate & 3 \\
\hline 3 & Values requirements & 1.78 & .098 & Moderate & 1 \\
\hline \multicolumn{2}{|l|}{ Total requirements } & 1.76 & .148 & Moderate \\
\hline
\end{tabular}

Table (5) refers to the reality of the level of application of the stages of decision-making based on evidence in social protection policies in some social units in Asyut Governorate. The average level of application (2.21) came with a standard deviation (.305) as determined by social workers working in the Program of Solidarity and Dignity. These steps were arranged as follows:

- The First Dimension: Identifying Problems with an average of (2.27) and a standard deviation of (.25)

- The Second Dimension: Implementing Evidence with an average of (2.22) and a standard deviation of (.351)

- The Third Dimensions: Gathering Evidence with an average of (2.21) and a standard deviation of (.311) 
The Egyptian Journal of Social Work (EJSW) https://ejsw.journals.ekb.eg/e

ISSN: 2356-9204

Vol 11, Issue.1, January2021

- The Fourth Dimension: Evaluating Evidence Impact with an average of (2.20) and a standard deviation of (.337)

- The Fifth Dimension: Appraising Evidence with an average of (2.14) and a standard deviation of (.28)

Considering the table 5, the results indicate that the overall average of the order of the stages of the process of decision-making based on evidence in social protection policies was (2.21) which is an average rate. This makes us accept the second hypothesis of the study which means that the application of decision-making based on evidence in social protection policies is expected to be an average one. Table (5) Shows the level of Steps evidence-based decision making

\begin{tabular}{|l|l|c|l|l|c|}
\hline No & Dimensions & mean & SD & Level & Rank \\
\hline 1 & Identifying problems & 2.27 & .25 & Moderate & 1 \\
\hline 2 & Gathering evidence: & 2.21 & .311 & -Moderate & 3 \\
\hline 3 & Appraising Evidence & 2.14 & .28 & Moderate & 5 \\
\hline 4 & Implement: Evidence & 2.22 & .351 & Moderate & 2 \\
\hline 5 & Evaluate Evidence impact & 2.20 & .337 & Moderate & 4 \\
\hline \multicolumn{2}{|l|}{ evidence-based decision making } & 2.21 & .305 & \multicolumn{2}{|c|}{ Moderate } \\
\hline
\end{tabular}

The table 6 indicate that there is no statistically significant relationship between the availability of the overall requirements (knowledge, skills, and value) and evidence-based decision-making in social protection policies as a whole (Identifying problems, Gathering evidence: Appraising Evidence, Implement: Evidence, Evaluate Evidence Impact). The value of Pearson correlation coefficient was (0.053) which is not statistically significant as it reached the significance of (.659) and therefore, it can be said that the third hypothesis of the study is incorrect. This means that there is no statistically significant relationship between the availability of requirements (knowledge, skills, and value) and decision-making based on evidence in social protection policies.

Table (6) Shows the correlation coefficient between Total requirements and evidence-based decision-making $n=71$

\begin{tabular}{|c|c|c|c|c|c|c|c|c|c|c|c|c|}
\hline \multirow{2}{*}{$\begin{array}{l}\text { EBDM } \\
\text { Total requirenents }\end{array}$} & \multicolumn{2}{|c|}{ Identifying problems } & \multicolumn{2}{|c|}{ Gathering evidence } & \multicolumn{2}{|c|}{ Appraising Evidence } & \multicolumn{2}{|c|}{ Implement: Evidence } & \multicolumn{2}{|c|}{$\begin{array}{c}\text { Evaluate Evidence } \\
\text { impost }\end{array}$} & \multicolumn{2}{|c|}{ Total EBDM } \\
\hline & \begin{tabular}{|l|} 
C Comelation \\
\end{tabular} & Sig & C Conclation & Sig & & Sig & & Sig & CComelation & $\mathrm{Sig}$ & tion $\mathrm{n}$ & Sig \\
\hline & & & & & & & & & & .451 & & 412 \\
\hline & & 3 & & & & & & & $.25)$ & .034 & & .041 \\
\hline Values & & 43 & & & & .082 & & .140 & .054. & 653 & .24 & .040 \\
\hline Toal requirements & .029. & .813 & .039 & .760 & .02 & .820 & .027. & .824 & .138 & .251 & 053 & 659 \\
\hline
\end{tabular}

*. Correlation is significant at the 0.05 level (2-tailed).

Table 7 shows that there is no statistically significant relationship between some of the personal and professional demographic variables of the social workers working in the Solidarity 


\begin{tabular}{||cr|}
\hline The Egyptian Journal of Social Work (EJSW) https://ejsw.journals.ekb.eg/e \\
ISSN: $2356-9204$ & Vol 11, Issue.1, January2021 \\
\hline
\end{tabular}

and Dignity Program and their orientation towards the decisionmaking process based on evidence in social protection policies at some social units. This indicates that the tendency of the social workers working in the Program of Solidarity and Dignity towards the application of decision-making based on evidence in social protection policies does not differ according to some demographic variables, such as (Gender, Social Status, Educational Level, Employment, Years of Experience, and Number of Courses). The results showed a counterproductive statistical relationship between the age of social workers working in the Solidarity and Dignity program and their tendency towards the application of evidence-based decision-making in social protection policies as the value of Pearson factor was (.238*) which is statistically functioning at the moral level of (0.05).

Based on the fore mentioned, it is clear that the fourth hypothesis of the study is incorrect. This means that there is no statistically significant relationship between the personal and professional variables of social workers working in the Solidarity and Dignity Program and their tendency towards the application of evidence-based decision-making.

Table (7) Shows the correlation coefficient between (demographical variables) and evidence-based decision making

\begin{tabular}{|l|c|c|c|}
\hline demographic variables & Coefficient & Correlation & Sig \\
\hline gender & Kendall's & $-.110-$ & .272 \\
\hline Age & Pearson & $-.238^{*}$ & .046 \\
\hline Social status & Kendall's & $-.082-$ & .399 \\
\hline Employment status & Kendall's & $-.018-$ & .851 \\
\hline Educational level & Gamma & $-.166-$ & .131 \\
\hline Years of Experience & Pearson & $-.238-$ & .082 \\
\hline Number of courses & Pearson & .064 & .713 \\
\hline
\end{tabular}

\section{DISCUSSION}

This study attempts to clarify the requirements of applied the Evidence-based decision making in Social protection policies in Egypt. Our study attempted to fill the gap associated with carrying out studies on the issue of Evidence-based decision making within an Arabic environment, and specifically across Egypt.

The results of the study indicated the importance of knowledge requirements as a basic requirement in guiding social workers working in the Program of Solidarity and Dignity towards decision-making based on evidence and the importance of the knowledge of the social workers with all what is new to increase their professional performance towards providing services to the 
The Egyptian Journal of Social Work (EJSW) https://ejsw.journals.ekb.eg/e

ISSN: 2356-9204

Vol 11, Issue.1, January2021

beneficiaries of social security units (customers). It also indicated the importance of the knowledge acquired by social workers in fields such as social protection and the basic conditions of eligibility for the Program of Solidarity and Dignity, the use of computers and databases, the preparation of reports on beneficiaries

This knowledge contributes to the development of the performance of social workers working in the Solidarity and Dignity Program in understanding the motives of the behavior of the benefiters of these units, the factors affecting it, and the importance of the work of social workers in social units. This includes all new knowledge, theories, and facts about decision-making based on evidence in social protection policies.

The results of this study agreed with what was indicated in the study of Spina (2018), which explained the need to pay attention to the development of practitioners' knowledge of evidence-based decisionmaking through ongoing development programs. It also focused on the need to integrate them into the content of courses. (Spina, 2018)

The results of the study showed the importance of skills as a major demand in decision-making based on evidence in social protection policies and the link of evidence-based planning to the skills and experiences that social workers in the Solidarity and Dignity Program should have. In addition, come the experiences of other employees and beneficiaries of the unit themselves (clients) such as communication skills, the choice of the best alternative to face the problem, social research skills, comparing alternatives and priorities, and the use of technology and computer to search databases and follow-up to serve the clients of the Solidarity and Dignity Program in social security units in Asyut governorate.

Professional skills are of the requirements for the professional performance of social workers working in the Solidarity and dignity Program. Professional skills are real products of what has been acquired through the knowledge base, principles, professional values, the importance of these skills in refining the personality of professional social workers, improving their professional performance, in addition to improving the services provided to the benefiters (Clients) for developing professional work within social security units.

These findings were agreed by Hollingworth et al.'s study that increased interest in training practitioners in computer skills as well as the use of available internet sources in evidence-based decisionmaking (Hollingworth et al., 2020). 
The Egyptian Journal of Social Work (EJSW) https://ejsw.journals.ekb.eg/e ISSN: 2356-9204

Vol 11, Issue.1, January2021

The results of the study showed the importance of professional values as a prerequisite in decision-making based on evidence in the formation of the behaviors and beliefs of social workers working in the program of Solidarity and Dignity. These values are important for providing services to the beneficiaries of these units (clients) whether these values are personal or organizational. The values of justice and equality are important when providing services, respecting individual differences, appreciating the feelings of the benefactors, maintaining the confidentiality of information, and respecting the privacy of customers to gain their trust when making a decision on the services of beneficiaries. (Smith \& Ash, 2012)

These results confirm the importance of the professional values that the social worker must rely on and the ability to apply them in his/her practice with all clients and how to provide services faster.

The results of the study revealed that the reality of the level of application of the stages of decision-making based on evidence in social protection policies in the social units of Asyut governorate came with an average of (2.21) and a standard deviation of (.305). They revealed that the most important indicators of the stages of decision-making based on evidence in social protection policies are in determining the problem in its various aspects and factors affecting it with identifying the evidence put forward to solve the problem. They considered its fit with time, material, and human possibilities available. They considered the professional and the organizational ethics in addition to the objectives and the regulations of institutions. They evaluated the evidence based on the criteria depending on the various aspects and factors affecting it with identifying the evidence put forward to solve the problem and fit it with the time and material and human possibilities available. They also considered the professional and the organizational ethics and objectives and regulations of institutions and then evaluated the evidence based on the criteria on the basis of the various aspects and factors affecting it. They considered the objectives and regulations of the institutions and then evaluated the evidence based on the criteria of the advantages and defects of each alternative and the implications of these alternatives and then the implementation of the chosen alternative and the importance of the participation of beneficiaries in social units in the implementation of this alternative and finally they do the follow up and evaluate the implementation of the alternative and bear the consequences of its implementation and evaluate the expected returns 
The Egyptian Journal of Social Work (EJSW) https://ejsw.journals.ekb.eg/e

ISSN: 2356-9204

Vol 11, Issue.1, January2021

from it and the reasons of the shortcomings and imbalance in the success of the alternative and avoid falling into mistakes.

The results of the study in Table (6) showed that there is no statistically significant relationship between the availability of the total requirements (knowledge, skill, and value) and evidence-based decision-making in social protection policies as a whole (identifying problems, gathering evidence, appraising evidence, implementing evidence, and evaluating evidence impact). The value of Pearson correlation coefficient was (053.) which is not statistically significant. The significance was (.659) which refers to the need of social workers, working in the Program of Solidarity and Dignity, for a set of knowledge, skills, and values. If this set is available, it contributes to evidence-based decision-making and the development of their professional performance within social security units. In contrast, if this set is not available, there is a need to satisfy them and provide them to the social workers working in the Program of Solidarity and Dignity through training programs.

The results of the study concluded that there is no statistically significant relationship between some of the personal and professional demographic variables of the social workers working in the Program of Solidarity and Dignity and their orientation towards the decisionmaking process based on evidence in social protection policies in some social units. This indicates that the tendency of social workers working in the Solidarity and Dignity Program towards the application of evidence-based decision-making in social protection policies does not differ according to some demographic variables (gender, social status, educational status, job, years of experience, or number of courses). There is no impact of personal factors on decision-making based on evidence within these social units.

\section{STUDY LIMITATION:}

There are clear limitations to this study. Although the study uses a purposive sample of social workers practicing in social protection policies across the Assiut governorate, it is inappropriate to generalize the results to all social workers. Samples from different geographical regions may provide different results. Secondly, the questionnaire was self-reported and did not capture the actual practices related to professional requirements. Thirdly, self-reporting measures introduces sources of errors and biases, such as participants consistently choosing high or low ratings. 
The Egyptian Journal of Social Work (EJSW) https://ejsw.journals.ekb.eg/e

\section{IMPLICATIONS FOR SOCIAL WORK PRACTICE}

The results of the current study showed the importance of the implementation of the evidence based decision-making process when carrying on the social protection policy with those who benefit from the services of the social protection policy in Egypt, thus we make the following recommendations:

1. Include Evidence-based decision-making issues in social work educational curriculums at both the undergraduate, graduate levels and continuous education programs.

2. Creating a series of training courses for social work students in all social work education phases with the purpose of applying Evidence-based decision making within a social work setting.

3. Carrying out future studies to identify the barriers which prevent applying the Evidence-based decision-making in social work practice settings, and especially family court settings.

4. Expanding the base of participation in decision-making based on evidence through the method of participation in decision-making.

5. The importance of using experts and consultants with specialization and experience in making the right decision.

6. The use of computers to save information within the units of social security and to coordinate between them and the administration and the directorate and to use it in making the right decision.

7. Conducting training courses for social workers working in social units on the mechanisms of evidence-based decision making.

\section{CONCLUSION}

The present study identifies the requirements of applied Evidencebased decision making in social protection policies in Egypt. The study referred to the need to review the educational curriculum with regard to the integration of the process of adopting the evidence-base decision making within the content of the courses in the education of social work in Egypt. It focused on training students and practitioners on the decision-making process based on evidence in dealing with clients in various fields of professional practice. There is a need to conduct further studies which are concerned with the evidence-based decision-making process in all areas of professional practice in the social work. 
The Egyptian Journal of Social Work (EJSW) https://ejsw.journals.ekb.eg/e

ISSN: 2356-9204

Vol 11, Issue.1, January2021

\section{REFERENCE}

Abdel Majid, H, Abdel Mawgoud,M, Qasem, A. (2008). Introduction to general practice in the service of the individual, Cairo, Dar Al-Muhandes for printing.

Abu El-Maati, M. (2002): Social planning and the model of social policy in Egyptian society. Cairo, Zahraa Al-Sharq Library.

Al-Ezzi, K. Y. (2011). Social Security for Workers in Arab Countries, (Unpublished Master Thesis), Cairo, Institute of Arab Research and Studies, League of Arab States, Egypt.

Al-Hout, A. (1990): Social Security and its Economic and Social Role, Benghazi, The Public House for Publishing and Distribution.

Al-Omari, A. (2000). Freedom from Poverty, "Social Security in the Legacy," Cairo, Center for Egyptian Women's Issues Studies.

Baba, V. V., \& HakemZadeh, F. (2012). Toward a theory of evidence-based decision making. Management Decision, 50(5), 832-867. doi:10.1108/00251741211227546

Bruce A. Thyer, Catherine N. Dulmus \& Karen M. Sowers (2013). Developing Evidence-Based Generalist Practice Skills, New Jersey John Wiley \& Sons, Inc.

El-Bayoumi, M. (1997): Social Legislation, Alexandria, Dar Al-Maarefa Al-Jamiiah.

Hamza, A. (2015). Social Policy, Amman, Dar Al-Masirah for Publishing, Distribution and Printing.

Hollingworth, S. A., Downey, L., Ruiz, F. J., Odame, E., Dsane-Selby, L., GyansaLutterodt, M., . . Chalkidou, K. (2020). What do we need to know? Data sources to support evidence-based decisions using health technology assessment in Ghana. Health Res Policy Syst, 18(1), 41. doi:10.1186/s12961-020-00550-8

Ibrahim, A. T. (2017). The reality of the participation of clients' social workers in taking remedial decisions in family dispute settlement offices in family courts. Journal of Studies in Social Work and Humanities, Faculty of Social Work, Helwan University, (46) (2), 48-71.

Katherine A. Stamatakis, Adriano Akira Ferreira Hino, Peg Allen, Amy McQueen, Rebekah R. Jacob, Elizabeth A. Baker, Ross C. Brownson. (2017). Results from a psychometric assessment of a new tool for measuring evidencebased decision making in public health organizations, Evaluation and Program Planning. (60) 17-23.

Majdzadeh, R., Yazdizadeh, B., Nedjat, S., Gholami, J., \& Ahghari, S. (2012). Strengthening evidence-based decision-making: is it possible without improving health system stewardship? Health Policy Plan, 27(6), 499-504. doi:10.1093/heapol/czr072

Mansour, H. (2010). Direct social service theories and measures, Alexandria, the modern university office.

Maynard, R. A. (2006). Presidential address: Evidence-based decision making: What will it take for the decision makers to care? Journal of Policy Analysis and Management, 25(2), 249-265.

Michael Lee Howell (2009). intake decision-making in child protective services: exploring the influence of decision-factors, race, and substance abuse A dissertation submitted in partial fulfillment of the requirements for the degree of Doctor of Philosophy at Virginia Commonwealth University. 
Ministry of Social Solidarity (2017). The reports of the Directorate of Social Affairs in Assiut.

O'Sullivan, T. (1999). Decision making in social work. London: MacMillan Press Ltd.

Payne, M. (2001). Knowledge bases and knowledge biases in social work. Journal of Social Work, 1(2), 133-146.

Smith-Rodden, M., \& Ash, I. K. (2012). Investigating the Psychological Effects of News Imagery: A Case for Evidence-based Decision Making and Practices. Visual Communication Quarterly, 19(1), 20-32. doi:10.1080/15551393.2012.656056

Social Solidarity (2018): retrieved from: www.moss.gov.egugn.

Spina, N. (2018). 'Once upon a time': examining ability grouping and differentiation practices in cultures of evidence-based decision-making. Cambridge Journal of Education, 49(3), 329-348.

Spurr, K., Dechman, G., Lackie, K., \& Gilbert, R. (2016). Creation of a Tool for Assessing Knowledge in Evidence-Based Decision-Making in Practicing Health Care Providers. The Journal of continuing education in the health professions, 36(3), $164-170$. https://doi.org/10.1097/CEH.0000000000000083

Stamatakis, K. A., Ferreira Hino, A. A., Allen, P., McQueen, A., Jacob, R. R., Baker, E. A., \& Brownson, R. C. (2017). Results from a psychometric assessment of a new tool for measuring evidence-based decision making in public health organizations. Eval Program Plann, 60, 17-23.

Stonebraker, I., \& Howard, H. A. (2018). Evidence-based decision-making: awareness, process and practice in the management classroom. Journal of Academic Librarianship, 44(1), 113-117

Wentworth, L., Mazzeo, C., \& Connolly, F. (2017). Research practice partnerships: a strategy for promoting evidence-based decision-making in education. Educational Research, 59(2), 241-255.

Zidan, A, Nasr, A, Ibrahim, A. (2016). Evidence-based practice in social work with the individual and the family, Alexandria, modern university office. 